\title{
Fixed Point Theorems of Binary Contraction Comparable Operators and an Application
}

\author{
Zhan Liu' ${ }^{1}$ and Chuanxi Zhu' \\ ${ }^{1}$ Statistics School, Southwestern University of Finance and Economics, Chengdu 611130, China
}

${ }^{2}$ Department of Mathematics, Nanchang University, Nanchang 330031, China

Correspondence should be addressed to Zhan Liu; 112020208002@2012.swufe.edu.cn

Received 15 June 2015; Revised 22 September 2015; Accepted 27 September 2015

Academic Editor: Juan R. Torregrosa

Copyright ( 2015 Z. Liu and C. Zhu. This is an open access article distributed under the Creative Commons Attribution License, which permits unrestricted use, distribution, and reproduction in any medium, provided the original work is properly cited.

\begin{abstract}
The aim of this paper is to present the concept of binary comparable operators in partially ordered Banach spaces and prove several fixed point theorems under some contractive conditions. The results of this paper can be used to investigate a large class of nonlinear problems. As an application, we study the existence of solution of a nonlinear integral equation.
\end{abstract}

\section{Introduction}

The Banach contraction principle [1] as a popular tool for solving problems in nonlinear analysis was invented in 1922. Since then, the study of fixed points of mappings with contractive property has been at the center of various research activities. For example, Liu and Zhu [2] studied the solvability of a binary operator equation satisfying certain contractive conditions; Romaguera [3] obtained several fixed point theorems of mappings satisfying some generalized contractive conditions. For more details on fixed point results of contractive type mappings and applications, we refer to Yan et al. [4], Mukherjea [5], Ran and Reurings [6], Hussain et al. [7], Amini-Harandi [8], Sintunavarat and Kumam [9], Nieto and Rodríguez-López [10, 11], and O'Regan and Saadati [12].

One of the common properties of the above results is that the involved operators must satisfy the monotone or mixed monotone conditions. In 2005, Zhang [13] studied an ordinal $L$-ordering symmetric contraction operator without the mixed monotone property and proved some coupled fixed point theorems. On the other hand, Qiao [14] investigated the fixed point theorems of the ordered contractive operators with the comparable property.

In the present paper, we introduce the concept of binary comparable operators, which can be seen as a generalization of the concept of mixed monotone operators and the concept of antimixed monotone operators. Using the iterative techniques $([15,16])$, we obtain several fixed point theorems for such operators under some contractive conditions. The results of this paper generalize several classical results in the literature. As an application, the existence of solution of an integral equation is presented.

For the sake of convenience, let us recall the following definitions and lemmas (see $[14,17,18]$ for more details and recent results).

Let $E$ be a real Banach space. A subset $P$ of $E$ is called a cone whenever the following conditions hold:

(i) $P$ is closed, nonempty, and $P \neq\{0\}$;

(ii) $a, b \in R, a, b \geq 0$, and $x, y \in P$ implies $a x+b y \in P$;

(iii) $P \cap(-P)=\{0\}$.

Given a cone $P \subset E$, we define a partial ordering $\leq$ with respect to $P$ by $x \leq y$ if and only if $y-x \in P$.

Let $E$ be a normed Banach space, which is partially ordered by a cone $P$. The cone $P$ is said to be normal if there exists a constant $N>0$, such that, for all $x, y \in E, \theta \leq x \leq y$ implies $\|x\| \leq N\|y\|$, where $\theta$ denotes the zero element of $E$.

Definition 1 (see [14]). For some $x, y \in E$, if $x \leq y$ or $y \leq x$ holds, $x$ and $y$ are said to be comparable. Moreover, one will write $x \vee y=y$ to indicate that $x \leq y$, while $x \vee y=x$ stand for $y \leq x$. 
Lemma 2 (see [14]). If $x, y \in E$ are comparable, then $x-y$ and $y-x$ are comparable, and

$$
\theta \leq(x-y) \vee(y-x) .
$$

Lemma 3 (see [14]). For some $x, y, z \in E$, if any two of them are comparable, then

$$
\begin{aligned}
(x-y) \vee(y-x) \leq & {[(x-z) \vee(z-x)] } \\
+ & {[(z-y) \vee(y-z)] . }
\end{aligned}
$$

Lemma 4 (see [14]). If, for each positive integer $n, x$ and $y_{n}$ are comparable and $\lim _{n \rightarrow \infty} y_{n} \rightarrow y_{0}$, then $x$ and $y_{0}$ are comparable.

Lemma 5 (see [14]). If, for each positive integer $n, x_{n}$ and $y_{n}$ are comparable and $\lim _{n \rightarrow \infty} x_{n} \rightarrow x_{0}, \lim _{n \rightarrow \infty} y_{n} \rightarrow y_{0}$, then $x_{0}$ and $y_{0}$ are comparable.

Definition 6. A binary operator $A: E \times E \rightarrow E$ is said to be comparable if, for all comparable pairs $x_{1}, x_{2} \in E$ and $y_{1}, y_{2} \in$ $E, A\left(x_{1}, y_{1}\right)$ and $A\left(x_{2}, y_{2}\right)$ are comparable.

Definition 7. A comparable operator $A: E \times E \rightarrow E$ is said to be $\alpha$-contractive, if, for all comparable pairs $x_{1}, x_{2} \in E$ and $y_{1}, y_{2} \in E$, there exists a constant $\alpha \in(0,1 / 2)$ such that

$$
\begin{aligned}
& {\left[A\left(x_{1}, y_{1}\right)-A\left(x_{2}, y_{2}\right)\right] \vee\left[A\left(x_{2}, y_{2}\right)-A\left(x_{1}, y_{1}\right)\right]} \\
& \quad \leq \alpha\left\{\left[\left(x_{1}-x_{2}\right) \vee\left(x_{2}-x_{1}\right)\right]\right. \\
& \left.\quad+\left[\left(y_{1}-y_{2}\right) \vee\left(y_{2}-y_{1}\right)\right]\right\} .
\end{aligned}
$$

\section{Main Results}

Theorem 8. Let $E$ be a real Banach space, $P$ a normal cone of $E$ with the normal constant $N$, and $\leq a$ partial order with respect to $P$. Let $A: E \times E \rightarrow E$ be demicontinuous. Suppose that the following two conditions are satisfied:

(i) A is $\alpha$-contractive and comparable, where $\alpha \in(0,1 / 2)$;

(ii) there exists a comparable pair $\left(x_{0}, y_{0}\right)$ in $E$, such that $x_{0}$ and $A\left(x_{0}, y_{0}\right), y_{0}$ and $A\left(y_{0}, x_{0}\right)$ are comparable.

Then $A$ has a fixed point $x^{*}$ in $E$; that is, $A\left(x^{*}, x^{*}\right)=x^{*}$. Moreover, the iterative sequences $x_{n}=A\left(x_{n-1}, y_{n-1}\right)$ and $y_{n}=$ $A\left(y_{n-1}, x_{n-1}\right)$ converge to $x^{*}$, and

$$
\begin{aligned}
& \left\|x_{0}-x^{*}\right\| \\
& \leq \frac{N}{2(1-2 \alpha)}\left(\left\|A\left(x_{0}, y_{0}\right)-x_{0}\right\|+\left\|A\left(y_{0}, x_{0}\right)-y_{0}\right\|\right), \\
& \left\|y_{0}-x^{*}\right\| \\
& \leq \frac{N}{2(1-2 \alpha)}\left(\left\|A\left(x_{0}, y_{0}\right)-x_{0}\right\|+\left\|A\left(y_{0}, x_{0}\right)-y_{0}\right\|\right) .
\end{aligned}
$$

Proof. Consider the iterative sequences

$$
\begin{gathered}
x_{1}=A\left(x_{0}, y_{0}\right), \\
\vdots \\
x_{n}=A\left(x_{n-1}, y_{n-1}\right) ; \\
y_{1}=A\left(y_{0}, x_{0}\right), \\
\vdots \\
y_{n}=A\left(y_{n-1}, x_{n-1}\right) ;
\end{gathered}
$$

$$
n=1,2, \ldots
$$

Since $x_{0}$ and $y_{0}$ are comparable and $A: E \times E \rightarrow E$ is a comparable operator, it is easy to verify that $x_{1}=$ $A\left(x_{0}, y_{0}\right)$ and $y_{1}=A\left(y_{0}, x_{0}\right)$ are comparable. By inductions, we can prove that $x_{n}$ and $y_{n}$ are comparable for any positive integer $n$.

Since $A: E \times E \rightarrow E$ is a $\alpha$-contractive comparable operator, we have

$$
\begin{aligned}
\left(x_{n}-y_{n}\right) \vee\left(y_{n}-x_{n}\right) \\
=\left[A\left(x_{n-1}, y_{n-1}\right)-A\left(y_{n-1}, x_{n-1}\right)\right] \\
\quad \vee\left[A\left(y_{n-1}, x_{n-1}\right)-A\left(x_{n-1}, y_{n-1}\right)\right] \\
\leq 2 \alpha\left[\left(x_{n-1}-y_{n-1}\right) \vee\left(y_{n-1}-x_{n-1}\right)\right] .
\end{aligned}
$$

If we continue in the same way, for each $n \in N$, we have

$$
\left(x_{n}-y_{n}\right) \vee\left(y_{n}-x_{n}\right) \leq 2^{n} \alpha^{n}\left[\left(x_{0}-y_{0}\right) \vee\left(y_{0}-x_{0}\right)\right] .
$$

By the normality of $P$, we have

$$
\left\|x_{n}-y_{n}\right\| \leq N 2^{n} \alpha^{n}\left\|x_{0}-y_{0}\right\| .
$$

Since $\left(x_{0}, y_{0}\right)$ is a comparable pair in $E$ and, moreover, $x_{0}$ and $A\left(x_{0}, y_{0}\right), y_{0}$ and $A\left(y_{0}, x_{0}\right)$ are comparable, we know that $A\left(x_{0}, y_{0}\right)$ and $A\left[A\left(x_{0}, y_{0}\right), A\left(y_{0}, x_{0}\right)\right]$, $A\left(y_{0}, x_{0}\right)$ and $A\left[A\left(y_{0}, x_{0}\right), A\left(x_{0}, y_{0}\right)\right]$ are comparable, which implies that $x_{1}$ and $x_{2}, y_{1}$ and $y_{2}$ are comparable. By induction, we know that $\left(x_{n}, x_{n+1}\right)$ and $\left(y_{n}, y_{n+1}\right)$ are all comparable pairs for each $n \in N$.

Furthermore, for each $n \in N$, we have

$$
\begin{aligned}
& \left(x_{n}-x_{n+1}\right) \vee\left(x_{n+1}-x_{n}\right)=\left[A\left(x_{n-1}, y_{n-1}\right)\right. \\
& \left.\quad-A\left(x_{n}, y_{n}\right)\right] \vee\left[A\left(x_{n}, y_{n}\right)-A\left(x_{n-1}, y_{n-1}\right)\right] \\
& \quad \leq \alpha\left\{\left[\left(x_{n}-x_{n-1}\right) \vee\left(x_{n-1}-x_{n}\right)\right]\right. \\
& \left.\quad+\left[\left(y_{n}-y_{n-1}\right) \vee\left(y_{n-1}-y_{n}\right)\right]\right\}, \\
& \left(y_{n}-y_{n+1}\right) \vee\left(y_{n+1}-y_{n}\right)=\left[A\left(y_{n-1}, x_{n-1}\right)\right. \\
& \left.\quad-A\left(y_{n}, x_{n}\right)\right] \vee\left[A\left(y_{n}, x_{n}\right)-A\left(y_{n-1}, x_{n-1}\right)\right] \\
& \quad \leq \alpha\left\{\left[\left(x_{n}-x_{n-1}\right) \vee\left(x_{n-1}-x_{n}\right)\right]\right. \\
& \left.\quad+\left[\left(y_{n}-y_{n-1}\right) \vee\left(y_{n-1}-y_{n}\right)\right]\right\} .
\end{aligned}
$$


By induction we can prove that

$$
\begin{aligned}
& \left(x_{n}-x_{n+1}\right) \vee\left(x_{n+1}-x_{n}\right) \\
& \quad \leq 2^{n-1} \alpha^{n}\left\{\left[\left(A\left(x_{0}, y_{0}\right)-x_{0}\right) \vee\left(x_{0}-A\left(x_{0}, y_{0}\right)\right)\right]\right. \\
& \left.\quad+\left[\left(A\left(y_{0}, x_{0}\right)-y_{0}\right) \vee\left(y_{0}-A\left(y_{0}, x_{0}\right)\right)\right]\right\}, \\
& \left(y_{n}-y_{n+1}\right) \vee\left(y_{n+1}-y_{n}\right) \\
& \quad \leq 2^{n-1} \alpha^{n}\left\{\left[\left(A\left(x_{0}, y_{0}\right)-x_{0}\right) \vee\left(x_{0}-A\left(x_{0}, y_{0}\right)\right)\right]\right. \\
& \left.\quad+\left[\left(A\left(y_{0}, x_{0}\right)-y_{0}\right) \vee\left(y_{0}-A\left(y_{0}, x_{0}\right)\right)\right]\right\} .
\end{aligned}
$$

Since $\alpha \in(0,1 / 2)$, we can prove that $\left\{x_{n}\right\}$ and $\left\{y_{n}\right\}$ are Cauchy sequences in $E$. Then there exist two points $x^{*}, y^{*} \in E$, such that

$$
\begin{aligned}
& x_{n} \longrightarrow x^{*}, \\
& y_{n} \longrightarrow y^{*} \\
& \quad(n \longrightarrow \infty) .
\end{aligned}
$$

Since $A$ is demicontinuous, $x_{n}=A\left(x_{n-1}, y_{n-1}\right)$ converges to $A\left(x^{*}, y^{*}\right)$ weakly and $y_{n}=A\left(y_{n-1}, x_{n-1}\right)$ converges to $A\left(y^{*}, x^{*}\right)$ weakly and thus $A\left(x^{*}, y^{*}\right)=x^{*}, A\left(y^{*}, x^{*}\right)=y^{*}$; that is, $\left(x^{*}, y^{*}\right)$ is a coupled fixed point of $A$.

Taking limit in (8) as $n \rightarrow \infty$, we get

$$
x^{*}=y^{*} .
$$

This means that

$$
A\left(x^{*}, x^{*}\right)=x^{*}
$$

Hence $x^{*}$ is a fixed point of $A$.

Moreover,

$$
\begin{aligned}
& \left\|x_{0}-x^{*}\right\|=\lim _{n \rightarrow \infty}\left\|x_{n}-x_{0}\right\| \leq \lim _{n \rightarrow \infty} \sum_{i=1}^{n}\left\|x_{i}-x_{i-1}\right\| \\
& \leq \sum_{i=1}^{\infty} \frac{N}{2} 2^{i-1} \alpha^{i-1}\left(\left\|A\left(x_{0}, y_{0}\right)-x_{0}\right\|\right. \\
& \left.+\left\|A\left(y_{0}, x_{0}\right)-y_{0}\right\|\right)=\frac{N}{2(1-2 \alpha)}\left(\| A\left(x_{0}, y_{0}\right)\right. \\
& \left.-x_{0}\|+\| A\left(y_{0}, x_{0}\right)-y_{0} \|\right) .
\end{aligned}
$$

By a similar method, we can prove

$$
\begin{aligned}
& \left\|y_{0}-x^{*}\right\| \\
& \leq \frac{N}{2(1-2 \alpha)}\left(\left\|A\left(x_{0}, y_{0}\right)-x_{0}\right\|+\left\|A\left(y_{0}, x_{0}\right)-y_{0}\right\|\right) .
\end{aligned}
$$

Then we complete the proof of Theorem 8 .

Theorem 9. Let $E$ be a real Banach space, $P$ a normal cone of $E$ with the normal constant $N$, and $\leq$ the partial order with respect to $P$. Suppose that the following two conditions are satisfied:

(i) $A: E \times E \rightarrow E$ is $\alpha$-contractive comparable one, where $\alpha \in(0,1 / 2)$;

(ii) there exists a comparable pair $\left(x_{0}, y_{0}\right)$ in $E$, such that $x_{0}$ and $x_{n}=A\left(x_{n-1}, y_{n-1}\right), y_{0}$ and $y_{n}=A\left(y_{n-1}, x_{n-1}\right)$ are comparable for each $n \in N$.

Then $A$ has a fixed point $x^{*}$ in $E$; that is, $A\left(x^{*}, x^{*}\right)=x^{*}$. Moreover, the iterative sequences $x_{n}=A\left(x_{n-1}, y_{n-1}\right)$ and $y_{n}=$ $A\left(y_{n-1}, x_{n-1}\right)$ converge to $x^{*}$, and

$$
\begin{aligned}
& \left\|x_{0}-x^{*}\right\| \\
& \leq \frac{N}{2(1-2 \alpha)}\left(\left\|A\left(x_{0}, y_{0}\right)-x_{0}\right\|+\left\|A\left(y_{0}, x_{0}\right)-y_{0}\right\|\right), \\
& \left\|y_{0}-x^{*}\right\| \\
& \leq \frac{N}{2(1-2 \alpha)}\left(\left\|A\left(x_{0}, y_{0}\right)-x_{0}\right\|+\left\|A\left(y_{0}, x_{0}\right)-y_{0}\right\|\right) .
\end{aligned}
$$

Proof. By a similar approach as in the proof of Theorem 8, we can prove that $\left\{x_{n}\right\}$ and $\left\{y_{n}\right\}$ are Cauchy sequences in $E$, and there exist two points $x^{*}, y^{*} \in E$, such that

$$
\begin{aligned}
& x_{n} \longrightarrow x^{*}, \\
& y_{n} \longrightarrow y^{*}
\end{aligned}
$$

$$
(n \longrightarrow \infty) \text {. }
$$

Furthermore

$$
x^{*}=y^{*} \text {. }
$$

We now prove that $x^{*}$ is a fixed point of $A$. For some $m, n \in N$, assume that $n<m$; then by condition (ii), we know that $x_{0}$ and $x_{m-n}=A\left(x_{m-n-1}, y_{m-n-1}\right)$, $y_{0}$ and $y_{m-n}=A\left(y_{m-n-1}, x_{m-n-1}\right)$ are comparable; hence $A\left(x_{0}, y_{0}\right)$ and $A\left(x_{m-n}, y_{m-n}\right), A\left(y_{0}, x_{0}\right)$ and $A\left(y_{m-n}, x_{m-n}\right)$ are comparable. If we continue in the same way, we can prove that $x_{n}$ and $x_{m}, y_{n}$ and $y_{m}$ are comparable. As $m \rightarrow \infty$, by Lemma 4 , we know that, for each $n \in N, x_{n}$ and $x^{*}, y_{n}$ and $y^{*}$ are comparable.

Hence $A\left(x_{n}, y_{n}\right)$ and $A\left(x^{*}, y^{*}\right), A\left(y_{n}, x_{n}\right)$ and $A\left(y^{*}, x^{*}\right)$ are comparable; furthermore

$$
\begin{aligned}
& {\left[A\left(x_{n}, y_{n}\right)-A\left(x^{*}, y^{*}\right)\right] \vee\left[A\left(x^{*}, y^{*}\right)-A\left(x_{n}, y_{n}\right)\right]} \\
& \quad \leq \alpha\left\{\left[\left(x_{n}-x^{*}\right) \vee\left(x^{*}-x_{n}\right)\right]\right. \\
& \left.\quad+\left[\left(y_{n}-y^{*}\right) \vee\left(y^{*}-y_{n}\right)\right]\right\} \\
& {\left[A\left(y_{n}, x_{n}\right)-A\left(y^{*}, x^{*}\right)\right] \vee\left[A\left(y^{*}, x^{*}\right)-A\left(y_{n}, x_{n}\right)\right]} \\
& \quad \leq \alpha\left\{\left[\left(x_{n}-x^{*}\right) \vee\left(x^{*}-x_{n}\right)\right]\right. \\
& \left.\quad+\left[\left(y_{n}-y^{*}\right) \vee\left(y^{*}-y_{n}\right)\right]\right\} .
\end{aligned}
$$


From the normality of $P$, we have

$$
\begin{aligned}
& \left\|A\left(x_{n}, y_{n}\right)-A\left(x^{*}, y^{*}\right)\right\| \\
& \leq \alpha\left\{\left\|x_{n}-x^{*}\right\|+\left\|y_{n}-y^{*}\right\|\right\} \\
& \left\|A\left(y_{n}, x_{n}\right)-A\left(y^{*}, x^{*}\right)\right\| \\
& \quad \leq \alpha\left\{\left\|x_{n}-x^{*}\right\|+\left\|y_{n}-y^{*}\right\|\right\} .
\end{aligned}
$$

Those imply that

$$
\begin{gathered}
\left\|x_{n+1}-A\left(x^{*}, y^{*}\right)\right\| \leq \alpha\left\{\left\|x_{n}-x^{*}\right\|+\left\|y_{n}-y^{*}\right\|\right\} \\
\left\|y_{n+1}-A\left(y^{*}, x^{*}\right)\right\| \leq \alpha\left\{\left\|x_{n}-x^{*}\right\|+\left\|y_{n}-y^{*}\right\|\right\}
\end{gathered}
$$

Taking limit in (21) as $n \rightarrow \infty$, we get $A\left(x^{*}, y^{*}\right)=x^{*}$, $A\left(y^{*}, x^{*}\right)=y^{*}$; that is, $\left(x^{*}, y^{*}\right)$ is a coupled fixed point of A.

By (18), we can prove that $x^{*}$ is a fixed point of $A$.

Using the same argument as that in the proof of Theorem 8 , we can obtain

$$
\begin{aligned}
& \left\|x_{0}-x^{*}\right\| \leq \frac{N}{2(1-2 \alpha)}\left(\left\|A\left(x_{0}, y_{0}\right)-x_{0}\right\|\right. \\
& \left.+\left\|A\left(y_{0}, x_{0}\right)-y_{0}\right\|\right) \\
& \left\|y_{0}-x^{*}\right\| \leq \frac{N}{2(1-2 \alpha)}\left(\left\|A\left(x_{0}, y_{0}\right)-x_{0}\right\|\right. \\
& \left.+\left\|A\left(y_{0}, x_{0}\right)-y_{0}\right\|\right) .
\end{aligned}
$$

Then we complete the proof of Theorem 9.

Theorem 10. Let $E$ be a Banach space and $P$ a normal cone in $E$ with the normal constant $N, u_{0}, v_{0} \in E$ with $u_{0} \leq v_{0}$, and $\left[u_{0}, v_{0}\right]$ an order interval. Suppose that $A:\left[u_{0}, v_{0}\right] \times\left[u_{0}, v_{0}\right] \rightarrow$ $\left[u_{0}, v_{0}\right]$ is $\alpha$-contractive and comparable, where $\alpha \in(0,1 / 2)$; then $A$ has a unique fixed point $u^{*}$ in $E$. Moreover, for any initial $\left(x_{0}, y_{0}\right) \in\left[u_{0}, v_{0}\right] \times\left[u_{0}, v_{0}\right]$, the iterative sequences $x_{n}=A\left(x_{n-1}, y_{n-1}\right)$ and $y_{n}=A\left(y_{n-1}, x_{n-1}\right)$ converge to $u^{*}$.

Proof. Consider the iterative sequences

$$
\begin{gathered}
u_{1}=A\left(u_{0}, v_{0}\right), \\
\vdots \\
u_{n}=A\left(u_{n-1}, v_{n-1}\right) ; \\
v_{1}=A\left(v_{0}, u_{0}\right), \\
\vdots \\
v_{n}=A\left(v_{n-1}, u_{n-1}\right) ;
\end{gathered}
$$$$
n=1,2, \ldots
$$

Since $u_{0}$ and $v_{0}$ are comparable and $A: E \times E \rightarrow E$ is a comparable operator, it is easy to verify that $u_{1}=$ $A\left(u_{0}, v_{0}\right)$ and $v_{1}=A\left(v_{0}, u_{0}\right)$ are comparable. By inductions, we can prove that $u_{n}$ and $v_{n}$ are comparable for any positive integer $n$.

Since $A: E \times E \rightarrow E$ is a $\alpha$-contractive comparable operator, we have

$$
\begin{aligned}
\left(u_{n}-v_{n}\right) \vee\left(v_{n}-u_{n}\right) & \\
= & {\left[A\left(u_{n-1}, v_{n-1}\right)-A\left(u_{n-1}, v_{n-1}\right)\right] } \\
& \vee\left[A\left(v_{n-1}, u_{n-1}\right)-A\left(u_{n-1}, v_{n-1}\right)\right] \\
\leq & 2 \alpha\left[\left(u_{n-1}-v_{n-1}\right) \vee\left(v_{n-1}-u_{n-1}\right)\right] .
\end{aligned}
$$

If we continue in the same way, for each $n \in N$, we have

$$
\left(u_{n}-v_{n}\right) \vee\left(v_{n}-u_{n}\right) \leq 2^{n} \alpha^{n}\left[\left(u_{0}-v_{0}\right) \vee\left(v_{0}-u_{0}\right)\right] .
$$

By the normality of $P$, we have

$$
\left\|u_{n}-v_{n}\right\| \leq N 2^{n} \alpha^{n}\left\|u_{0}-v_{0}\right\| .
$$

Since $u_{0} \leq v_{0}$, we know that $u_{0}$ and $u_{1}=A\left(u_{0}, v_{0}\right), v_{0}$ and $v_{1}=A\left(v_{0}, u_{0}\right)$ are comparable; thus $A\left(u_{0}, v_{0}\right)$ and $A\left(u_{1}, v_{1}\right)$, $A\left(v_{0}, u_{0}\right)$ and $A\left(v_{1}, u_{1}\right)$ are comparable, which implies that $u_{1}$ and $u_{2}, v_{1}$ and $v_{2}$ are comparable. By induction, we know that $\left(u_{n}, u_{n+1}\right)$ and $\left(v_{n}, v_{n+1}\right)$ are all comparable pairs for each $n \in$ N.

Furthermore, for each $n \in N$, we have

$$
\begin{aligned}
& \left(u_{n}-u_{n+1}\right) \vee\left(u_{n+1}-u_{n}\right)=\left[A\left(u_{n-1}, v_{n-1}\right)\right. \\
& \left.\quad-A\left(u_{n}, v_{n}\right)\right] \vee\left[A\left(u_{n}, y_{n}\right)-A\left(u_{n-1}, v_{n-1}\right)\right] \\
& \quad \leq \alpha\left\{\left[\left(u_{n}-u_{n-1}\right) \vee\left(u_{n-1}-u_{n}\right)\right]\right. \\
& \left.+\left[\left(v_{n}-v_{n-1}\right) \vee\left(v_{n-1}-v_{n}\right)\right]\right\} \\
& \quad \leq \alpha\left\{\left[A\left(u_{n-1}, v_{n-1}\right)-A\left(u_{n-2}, v_{n-2}\right)\right]\right. \\
& \vee\left[A\left(u_{n-2}, y_{n-2}\right)-A\left(u_{n-1}, v_{n-1}\right)\right] \\
& +\left[A\left(v_{n-1}, u_{n-1}\right)-A\left(v_{n-2}, u_{n-2}\right)\right] \\
& \left.\quad \vee\left[A\left(v_{n-2}, u_{n-2}\right)-A\left(v_{n-1}, u_{n-1}\right)\right]\right\} \\
& \quad \leq 2 \alpha^{2}\left\{\left[\left(u_{n-1}-u_{n-2}\right) \vee\left(u_{n-2}-u_{n-1}\right)\right]\right. \\
& \left.\quad+\left[\left(v_{n-1}-v_{n-2}\right) \vee\left(v_{n-2}-v_{n-1}\right)\right]\right\} \leq \cdots \\
& \quad \leq 2^{n-1} \alpha^{n}\left\{\left[\left(u_{1}-u_{0}\right) \vee\left(u_{0}-u_{1}\right)\right]\right. \\
& \left.+\left[\left(v_{1}-v_{0}\right) \vee\left(v_{0}-v_{1}\right)\right]\right\} \\
& \left.\quad+v_{n}-v_{n+1}\right) \vee\left(v_{n+1}-v_{n}\right) \\
& \quad \leq 2^{n-1} \alpha^{n}\left\{\left[\left(u_{1}-u_{0}\right) \vee\left(u_{0}-u_{1}\right)\right]\right. \\
& \left.+\left[\left(v_{1}-v_{0}\right) \vee\left(v_{0}-v_{1}\right)\right]\right\} .
\end{aligned}
$$

By the normality of $P$, we have

$$
\begin{gathered}
\left\|u_{n+1}-u_{n}\right\| \leq N 2^{n-1} \alpha^{n}\left\|u_{1}-u_{0}\right\| \\
\left\|v_{n+1}-v_{n}\right\| \leq N 2^{n-1} \alpha^{n}\left\|v_{1}-v_{0}\right\| .
\end{gathered}
$$


For $\alpha \in(0,1 / 2)$, we can prove that $\left\{u_{n}\right\}$ and $\left\{v_{n}\right\}$ are Cauchy sequences.

Since $\left\{u_{n}\right\},\left\{v_{n}\right\} \subset\left[u_{0}, v_{0}\right]$, there exist two points $u^{*}, v^{*}$ in $\left[u_{0}, v_{0}\right]$, such that

$$
\begin{aligned}
& u_{n} \longrightarrow u^{*}, \\
& v_{n} \longrightarrow v^{*} \\
& \quad(n \longrightarrow \infty) .
\end{aligned}
$$

Taking limit in (26) as $n \rightarrow \infty$, we get

$$
u^{*}=v^{*} \text {. }
$$

We now prove that $u^{*}$ is a fixed point of $A$. For some $m, n \in N$, assume that $n<m$; since $\left\{u_{n}\right\},\left\{v_{n}\right\} \subset$ $\left[u_{0}, v_{0}\right]$, we know that $u_{0}$ and $u_{m-n}=A\left(u_{m-n-1}, v_{m-n-1}\right)$, $v_{0}$ and $v_{m-n}=A\left(v_{m-n-1}, u_{m-n-1}\right)$ are comparable; hence $A\left(u_{0}, v_{0}\right)$ and $A\left(u_{m-n}, v_{m-n}\right), A\left(v_{0}, u_{0}\right)$ and $A\left(v_{m-n}, u_{m-n}\right)$ are comparable. If we continue in the same way, we can prove that $u_{n}$ and $u_{m}, v_{n}$ and $v_{m}$ are comparable. As $m \rightarrow \infty$, by Lemma 4, we know that, for each $n \in N, u_{n}$ and $u^{*}, v_{n}$ and $v^{*}$ are comparable.

Hence $A\left(u_{n}, v_{n}\right)$ and $A\left(u^{*}, v^{*}\right), A\left(v_{n}, u_{n}\right)$ and $A\left(u^{*}, v^{*}\right)$ are comparable; furthermore

$$
\begin{aligned}
& {\left[A\left(u_{n}, v_{n}\right)-A\left(u^{*}, v^{*}\right)\right] \vee\left[A\left(u^{*}, v^{*}\right)-A\left(u_{n}, v_{n}\right)\right]} \\
& \quad \leq \alpha\left\{\left[\left(u_{n}-u^{*}\right) \vee\left(u^{*}-u_{n}\right)\right]\right. \\
& \left.\quad+\left[\left(v_{n}-v^{*}\right) \vee\left(v^{*}-v_{n}\right)\right]\right\} \\
& {\left[A\left(v_{n}, u_{n}\right)-A\left(v^{*}, u^{*}\right)\right] \vee\left[A\left(v^{*}, u^{*}\right)-A\left(v_{n}, u_{n}\right)\right]} \\
& \quad \leq \alpha\left\{\left[\left(u_{n}-u^{*}\right) \vee\left(u^{*}-u_{n}\right)\right]\right. \\
& \left.\quad+\left[\left(v_{n}-v^{*}\right) \vee\left(v^{*}-v_{n}\right)\right]\right\} .
\end{aligned}
$$

From the normality of $P$, we have

$$
\begin{aligned}
& \left\|A\left(u_{n}, v_{n}\right)-A\left(u^{*}, v^{*}\right)\right\| \\
& \leq N \alpha\left\{\left\|u_{n}-u^{*}\right\|+\left\|v_{n}-v^{*}\right\|\right\} \\
& \left\|A\left(v_{n}, u_{n}\right)-A\left(v^{*}, u^{*}\right)\right\| \\
& \quad \leq N \alpha\left\{\left\|u_{n}-u^{*}\right\|+\left\|v_{n}-v^{*}\right\|\right\} .
\end{aligned}
$$

This implies that

$$
\begin{gathered}
\left\|u_{n+1}-A\left(u^{*}, v^{*}\right)\right\| \leq N \alpha\left\{\left\|u_{n}-u^{*}\right\|+\left\|v_{n}-v^{*}\right\|\right\} \\
\left\|v_{n+1}-A\left(v^{*}, u^{*}\right)\right\| \leq N \alpha\left\{\left\|u_{n}-u^{*}\right\|+\left\|v_{n}-v^{*}\right\|\right\} .
\end{gathered}
$$

Taking limit in (33) as $n \rightarrow \infty$, we get $A\left(u^{*}, v^{*}\right)=u^{*}$, $A\left(v^{*}, u^{*}\right)=v^{*}$; that is, $\left(u^{*}, v^{*}\right)$ is a coupled fixed point of A.

By (30), we can prove that $u^{*}$ is a fixed point of $A$.

For any initial $\left(x_{0}, y_{0}\right) \in\left[u_{0}, v_{0}\right] \times\left[u_{0}, v_{0}\right]$, we construct iterative sequences $x_{n}=A\left(x_{n-1}, y_{n-1}\right)$ and $y_{n}=$ $A\left(y_{n-1}, x_{n-1}\right), n=1,2, \ldots$. Since $u_{0} \leq x_{0}, y_{0} \leq v_{0}$, that is, $x_{0}$ and $u_{0}, y_{0}$ and $v_{0}$ are comparable, we know that $A\left(x_{0}, y_{0}\right)$ and
$A\left(u_{0}, v_{0}\right), A\left(y_{0}, x_{0}\right)$ and $A\left(v_{0}, u_{0}\right)$ are comparable, which mean that $x_{1}$ and $u_{1}, y_{1}$ and $v_{1}$ are comparable. By inductions, we know that $x_{n}$ and $u_{n}, y_{n}$ and $v_{n}$ are comparable for each $n \in N$. Moreover,

$$
\begin{aligned}
\left(x_{n}\right. & \left.-u_{n}\right) \vee\left(u_{n}-x_{n}\right)=\left[A\left(x_{n}, y_{n}\right)-A\left(u_{n}, v_{n}\right)\right] \\
& \vee \\
\quad & \left.\leq A\left(u_{n}, v_{n}\right)-A\left(x_{n}, y_{n}\right)\right] \\
& \leq \alpha\left\{\left(u_{n}-x_{n}\right) \vee\left(x_{n}-u_{n}\right)\right] \\
& \left.+\left[\left(v_{n}-y_{n}\right) \vee\left(y_{n}-v_{n}\right)\right]\right\} \\
& \leq \alpha\left\{\left[A\left(u_{n-1}, v_{n-1}\right)-A\left(x_{n-1}, y_{n-1}\right)\right]\right. \\
& \vee\left[A\left(x_{n-1}, y_{n-1}\right)-A\left(u_{n-1}, v_{n-1}\right)\right] \\
& +\left[A\left(v_{n-1}, u_{n-1}\right)-A\left(y_{n-1}, x_{n-1}\right)\right] \\
& \left.\vee\left[A\left(y_{n-1}, x_{n-1}\right)-A\left(v_{n-1}-u_{n-1}\right)\right]\right\} \\
& \leq 2 \alpha^{2}\left\{\left[\left(u_{n-1}-x_{n-1}\right) \vee\left(x_{n-1}-u_{n-1}\right)\right]\right. \\
& \left.+\left[\left(v_{n-1}-y_{n-1}\right) \vee\left(y_{n-1}-v_{n-1}\right)\right]\right\} \leq \ldots \\
& \leq 2^{n} \alpha^{n+1}\left\{\left[\left(u_{0}-x_{0}\right) \vee\left(u_{0}-x_{0}\right)\right]\right. \\
& \left.+\left[\left(y_{0}-v_{0}\right) \vee\left(v_{0}-y_{0}\right)\right]\right\} \\
& \left.+\left[\left(y_{0}-v_{0}\right) \vee\left(v_{0}-y_{0}\right)\right]\right\} . \\
& \leq 2^{n} \alpha^{n+1}\left\{\left[\left(u_{0}-x_{0}\right) \vee\left(u_{0}-x_{0}\right)\right]\right. \\
& \left.\left.-v_{n}\right) y_{n}\right)
\end{aligned}
$$

From the normality of $P$, we have

$$
\begin{gathered}
\left\|u_{n}-x_{n}\right\| \leq N 2^{n} \alpha^{n+1}\left\{\left\|u_{0}-x_{0}\right\|+\left\|y_{0}-v_{0}\right\|\right\} \\
\left\|v_{n}-y_{n}\right\| \leq N 2^{n} \alpha^{n+1}\left\{\left\|u_{0}-x_{0}\right\|+\left\|y_{0}-v_{0}\right\|\right\} .
\end{gathered}
$$

This implies that

$$
\begin{aligned}
& x_{n} \longrightarrow u^{*}, \\
& y_{n} \longrightarrow v^{*}\left(u^{*}\right) \\
& \quad(n \longrightarrow \infty) .
\end{aligned}
$$

For the uniqueness, we assume that there exists a point $\omega^{*} \epsilon$ $\left[u_{0}, v_{0}\right]$, such that $A\left(\omega^{*}, \omega^{*}\right)=\omega^{*}$. Construct the iterative sequence as $\omega_{1}=A\left(\omega^{*}, \omega^{*}\right), \omega_{2}=A\left(\omega_{1}, \omega_{1}\right), \ldots$, and $\omega_{n}=$ $A\left(\omega_{n-1}, \omega_{n-1}\right), \ldots$, and we know that $\omega_{n} \rightarrow u^{*}(n \rightarrow \infty)$. On the other hand, for $\omega^{*}=A\left(\omega^{*}, \omega^{*}\right), \omega^{*}=\omega_{1}=\cdots=\omega_{n}$, and hence $\omega^{*}=u^{*}$.

Then we complete the proof of Theorem 10 .

Remark 11. It is easy to verify that mixed monotone operators and antimixed monotone operators are precisely comparable operators. However, a comparable operator is not necessarily a mixed monotone operator or an antimixed monotone operator. Thus, the fixed point theorems in this work generalize and extend the fixed point theorems of mixed monotone operators and antimixed monotone operators. 


\section{Applications}

As an application, we consider the nonlinear Hammerstein integral equation of the following form.

Let $I$ be the closed unit interval $[0,1]$ in $R$. Consider the following integral equation:

$$
\begin{aligned}
x(s) & =A(x(s), y(s)) \\
& =\int_{0}^{s} \frac{k(s, t)}{s^{2}-t^{2}} \cdot \frac{x(t)+x(t) y(t)-1}{1+y(t)} d t, \quad s \in I .
\end{aligned}
$$

Suppose that $k(s, t): I \times I \rightarrow R^{+}$is continuous about $s$ and bounded measurable about $t$ and, moreover, nonnegative on $[0,1] \times[0,1]$ and $\alpha=\sup _{t \in I} \int_{0}^{1}\left(k(s, t) /\left(s^{2}-t^{2}\right)\right) d t<1 / 2$; then (37) has a unique solution $x^{*}(s)$.

Proof. Let $E=C[0,1]$ denote the Banach space of all real valued continuous functions $\varphi$ on $[0,1]$, with $\|\varphi\|=$ $\sup _{s \in[0,1]}|\varphi(s)|$, and let $P=\{\varphi \in E \mid \varphi(s) \geq 0, s \in[0,1]\}$. Clearly, $P$ is a normal cone of $E$ with the normal constant $N=1$.

We transform integral equation (37) to the form

$$
\begin{aligned}
x(s) & =A(x(s), y(s)) \\
& =\int_{0}^{1} \frac{k(s, t)}{s^{2}-t^{2}}\left[x(t)-\frac{1}{1+y(t)}\right] d t .
\end{aligned}
$$

Since $k(s, t) /\left(s^{2}-t^{2}\right)$ is nonnegative on $[0,1] \times[0,1]$, we get that $A$ is a binary operator from $[0,1] \times[0,1]$ to $[0,1]$, and apparently $A$ is comparable.

For $0 \leq x_{1}(s), x_{2}(s), y_{1}(s), y_{2}(s) \leq 1$, we get

$$
\begin{aligned}
& {\left[A\left(x_{1}, y_{1}\right)-A\left(x_{2}, y_{2}\right)\right] \vee\left[A\left(x_{2}, y\right)-A\left(x_{1}, y_{1}\right)\right]} \\
& \quad=\left|A\left(x_{1}, y_{1}\right)-A\left(x_{2}, y_{2}\right)\right| \\
& \quad=\int_{0}^{1} \frac{R(s, t)}{s^{2}-t^{2}}\left|x_{1}(t)-x_{2}(t)\right|+\frac{\left|y_{1}(t)-y_{2}(t)\right|}{\left(1+y_{1}(t)\right)} d t \\
& \quad \leq \alpha\left(\left|x_{1}(t)-x_{2}(t)\right|+\left|y_{1}(t)-y_{2}(t)\right|\right) .
\end{aligned}
$$

Then we obtain that $A$ is $\alpha$-contractive. According to Theorem 10, we can prove that the integral equation (37) has a unique solution.

Remark 12. The operator $A(x, y)$ defined by (37) is a comparable operator, but $A$ does not satisfy the mixed monotone or antimixed monotone condition. However, by Theorem 10 of this work, we can easily get the conclusion. Thus, from this application, it is shown that some of the results in this work generalize and extend the corresponding results of mixed monotone operators and antimixed monotone operators again.

\section{Conflict of Interests}

The authors declare that there is no conflict of interests regarding the publication of this paper.

\section{Acknowledgments}

This work is supported by the Fundamental Research Funds for the Central Universities, China (no. JBK1307050), and the National Natural Science Foundation of China (no. 11361042).

\section{References}

[1] S. Banach, "Sur les opérations dans les ensembles abstraits et leur application aux équations intégrales," Fundamenta Mathematicae, vol. 3, no. 1, pp. 133-181, 1922.

[2] Z. Liu and C. X. Zhu, "Solvability theorems with applications of an operator equation in partial order space," Acta Mathematica Scientia A, vol. 52, no. 6, pp. 1181-1188, 2009.

[3] S. Romaguera, "Fixed point theorems for generalized contractions on partial metric spaces," Topology and Its Applications, vol. 159, no. 1, pp. 194-199, 2012.

[4] F. Yan, Y. Su, and Q. Feng, "A new contraction mapping principle in partially ordered metric spaces and applications to ordinary differential equations," Fixed Point Theory and Applications, vol. 2012, article 152, 2012.

[5] A. Mukherjea, "Contractions and completely continuous mappings," Nonlinear Analysis-Theory, Methods \& Applications, vol. 1, no. 3, pp. 235-247, 1977.

[6] A. C. M. Ran and M. C. B. Reurings, "A fixed point theorem in partially ordered sets and some applications to matrix equations," Proceedings of the American Mathematical Society, vol. 132, no. 5, pp. 1435-1443, 2004.

[7] N. Hussain, V. Berinde, and N. Shafqat, "Common fixed point and approximation results for generalized $\phi$-contractions," Fixed Point Theory, vol. 10, no. 1, pp. 111-124, 2009.

[8] A. Amini-Harandi, "Coupled and tripled fixed point theory in partially ordered metric spaces with application to initial value problem," Mathematical and Computer Modelling, vol. 57, no. 910, pp. 2343-2348, 2013.

[9] W. Sintunavarat and P. Kumam, "Coupled coincidence and coupled common fixed point theorems in partially ordered metric spaces," Thai Journal of Mathematics, vol. 10, no. 3, pp. 551-563, 2012.

[10] J. J. Nieto and R. Rodríguez-López, "Contractive mapping theorems in partially ordered sets and applications to ordinary differential equations," Order, vol. 22, no. 3, pp. 223-239, 2005.

[11] J. J. Nieto and R. Rodríguez-López, "Existence and uniqueness of fixed point in partially ordered sets and applications to ordinary differential equations," Acta Mathematica SinicaEnglish Series, vol. 23, no. 12, pp. 2205-2212, 2007.

[12] D. O'Regan and R. Saadati, "Nonlinear contraction theorems in probabilistic spaces," Applied Mathematics and Computation, vol. 195, no. 1, pp. 86-93, 2008.

[13] X. Zhang, "Fixed point of ordered contractive maps," Acta Mathematica Scientia A, vol. 48, no. 5, pp. 973-978, 2005. 
[14] B. Qiao, "Fixed point theorems on nonlinear binary operator equations with applications," Discrete Dynamics in Nature and Society, vol. 2014, Article ID 241942, 4 pages, 2014.

[15] J. F. Traub, Iterative Methods for the Solution Of Equations, Prentice-Hall, Englewood Cliffs, New Jersey, NJ, USA, 1964.

[16] D. K. Lika, "On the solution of nonlinear operator equations by a class of iterative processes," Siberian Mathematical Journal, vol. 11, no. 4, pp. 709-713, 1970.

[17] D. J. Guo, Nonlinear Functional Analysis, Shandong Science Technology Publishing House, Shandong, China, 1985 (Chinese).

[18] H. H. Scharfer, Topological Vector Space, Springer, New York, NY, USA, 1971. 


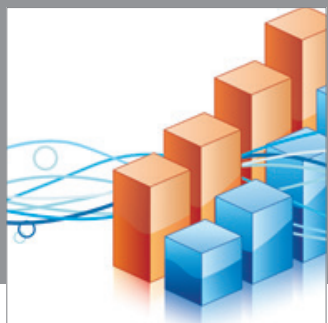

Advances in

Operations Research

mansans

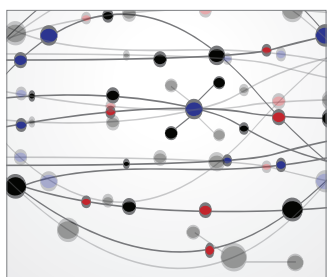

The Scientific World Journal
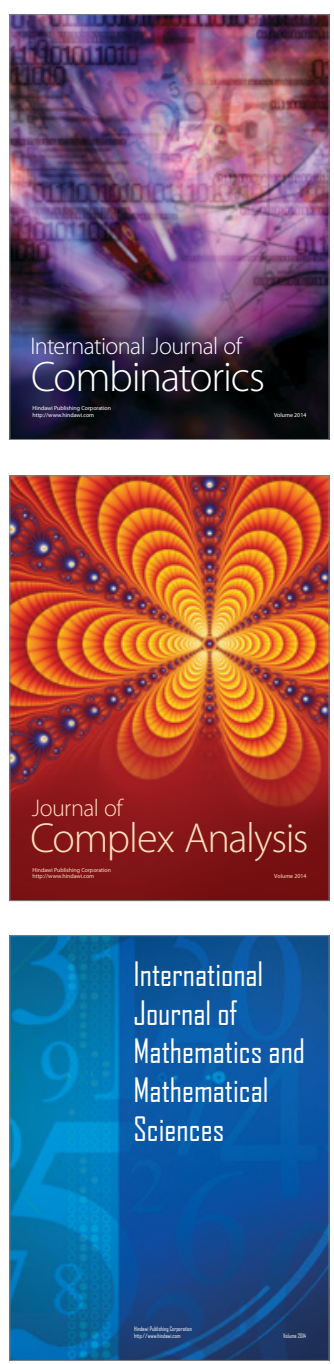
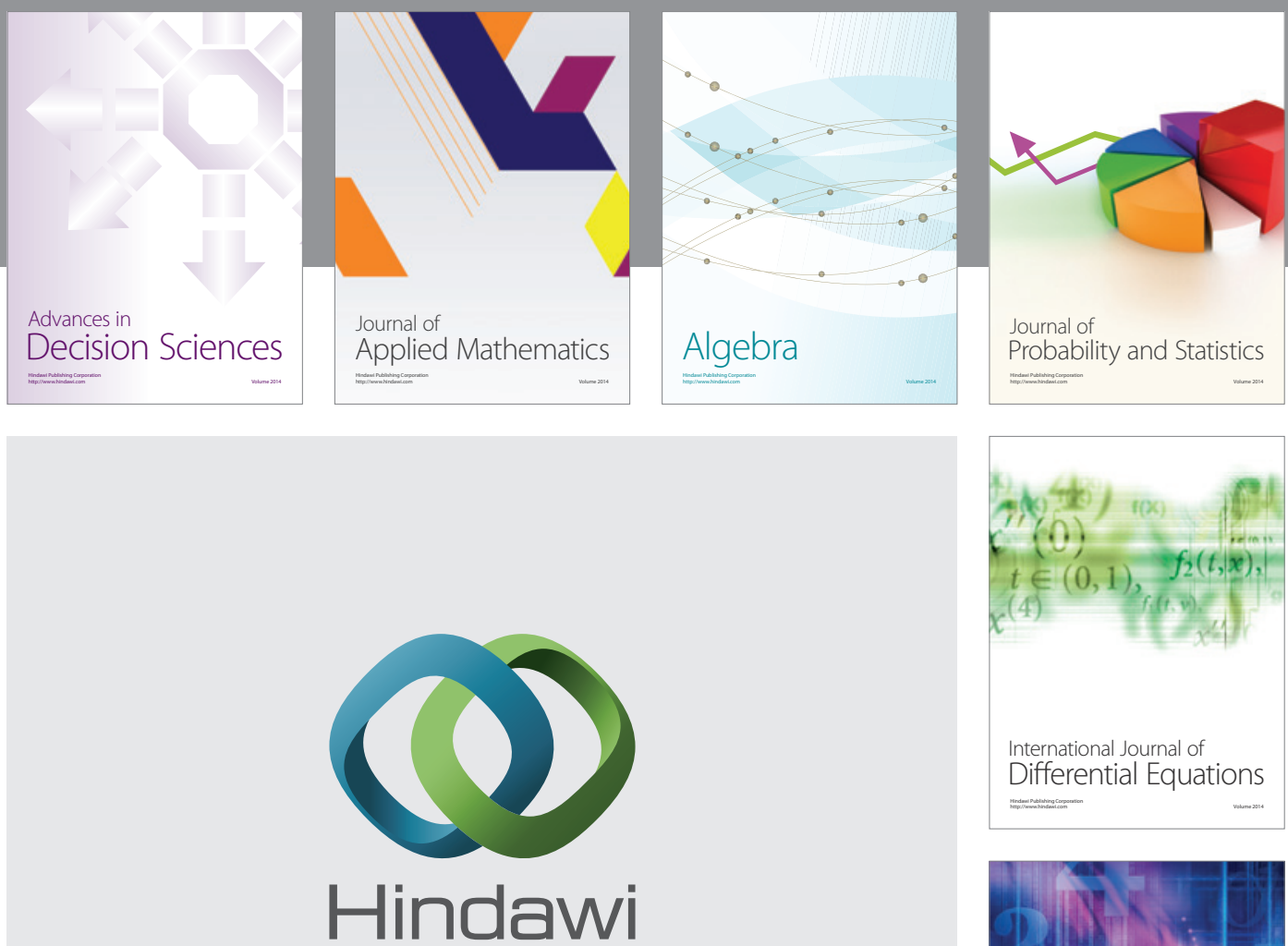

Submit your manuscripts at http://www.hindawi.com
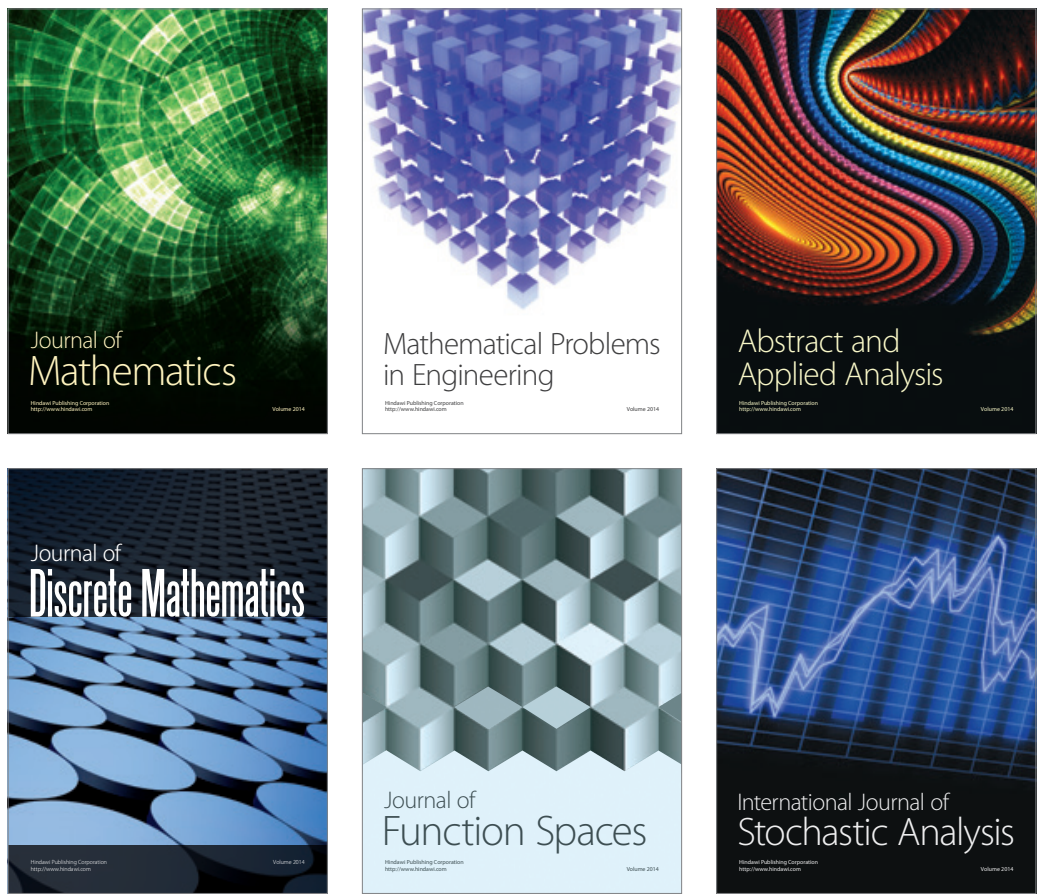

Journal of

Function Spaces

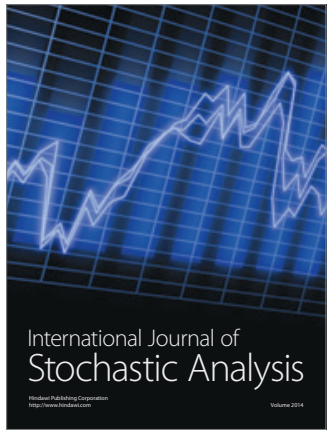

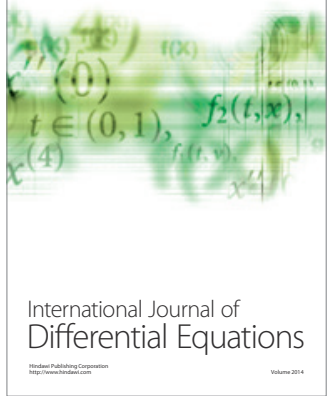
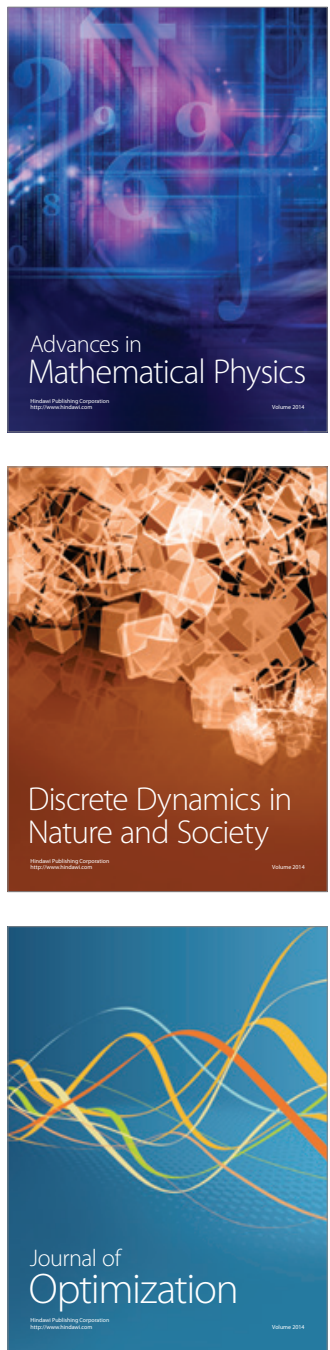